\title{
Pemantauan Pelaksanaan Asesmen Nasional Berbasis Komputer (ANBK) Sekolah Dasar Binaan Kecamatan Kopang Kabupaten Lombok Tengah Tahun 2021
}

\author{
Ahmad \\ Pengawas SD Kecamatan Kopang, Kabupaten Lombok Tengah - Provinsi NTB \\ *Corresponding Author. Email: ahmad1969.spdsdmpd@gmail.com
}

\begin{abstract}
The purpose of this study is to describe the monitoring of the Article History
Implementation of the Computer-Based National Assessment (ANBK) at the Received: 29-11-2021

Kopang District Primary Schools in 2021. The research method used is a Revised: 25-12-2021

descriptive method. The research data collection techniques used were Accepted: 30-12-2021

observation, interviews, and documentation. While the data analysis technique Published: 07-01-2022

used descriptive qualitative and quantitative analysis. The results of the study indicate that in order to improve the quality and quantity of the implementation of ANBK in the future, it is necessary to: (1) Improve the competence of educators and education staff in preparing literacy and numeracy-oriented questions in each subject through workshops. (2) Capacity building of educators and education staff in implementing school digitization through IHT. (3) Increasing the provision of ANBK facilities and infrastructure by procuring at least one IT
\end{abstract} laboratory space in one school cluster through DAK. (4) Increasing the availability of computer/laptop equipment through the use of Regular/Affirmative/Performance BOS funds. (5) Capacity building of school principals in school management. (6) Increasing the capacity of school supervisors in academic supervision and managerial supervision. (7) Empowerment of KKG, KKKS and KKPS forums in completing their respective main tasks and functions.

Abstrak: Tujuan penelitian ini adalah untuk mendeskripsikan pemantauan pelaksanaan asesmen nasional berbasis komputer (ANBK) bagi Sekolah Dasar Binaan Kecamatan Kopang Tahun 2021. Metode penelitian yang digunakan adalah metode deskriptif. Teknik pengumpulan datanya adalah observasi, wawancara, dan dokumentasi. Sedangkan teknik analisis datanya menggunakan analisis deskriptif kualitatif dan kuantitatif. Hasil penelitian menunjukkan bahwa untuk dapat meningkatkan kualitas dan kuantitas mutu pelaksanan ANBK di masa mendatang sangat perlu untuk : (1) Peningkatan kompetensi pendidik dan tenaga kependidikan dalam menyusun soal-soal yang berorientasi literasi dan numerasi pada setiap mata pelajaran melalui workshop. (2) Peningkatan kapasitas pendidik dan tenaga kependidikan dalam menerapkan digitalisasi sekolah melalui IHT. (3) Peningkatan penyediaan sarana dan prasarana ANBK dengan pengadaan ruang laboratorium IT minimal satu unit dalam satu gugus sekolah melalui DAK.

\section{Sejarah Artikel}

Diterima: 29-11-2021

Direvisi: 25-12-2021

Disetujui: 30-12-2021

Diterbitkan: 07-01-2022

\section{Kata Kunci:}

Pemantauan, Asesmen Nasional, ANBK, Sekolah Dasar. (4) Peningkatan ketersedian perangkat computer/laptop melalui pemanfaatan dana BOS Reguler/Afirmasi/Kinerja. (5) Peningkatan kapasitas kepala sekolah dalam manajemen pengelolaan sekolah. (6) Peningkatan kapasitas pengawas sekolah dalam pengawasan akademik dan pengawasan manajerial. (7) Pemberdayaan wadah KKG, KKKS dan KKPS dalam menyelesaikan tugas pokok dan fungsi masing-masing.

How to Cite: Ahmad, A. (2022). Pemantauan Pelaksanaan Asesmen Nasional Berbasis Komputer (ANBK) Sekolah Dasar Binaan Kecamatan Kopang Kabupaten Lombok Tengah Tahun 2021. Jurnal Paedagogy, 9(1), 34-44. doi:https://doi.org/10.33394/jp.v9i1.4619

do] https://doi.org/10.33394/jp.v9i1.4619

This is an open-access article under the CC-BY-SA License.

\section{Pendahuluan}

Undang-undang Nomor 20 Tahun 2003 tentang Sistem Pendidikan Nasional menyatakan bahwa sistem pendidikan nasional adalah keseluruhan komponen pendidikan 
yang saling terkait secara terpadu untuk mencapai tujuan pendidikan nasional, yaitu untuk mengembangkan kemampuan serta meningkatkan mutu kehidupan dan martabat manusia Indonesia. Selanjutnya, amanat Peraturan Pemerintah Republik Indonesia Nomor 19 Tahun 2005, sebagaimana diubah dua kali, terakhir dengan Peraturan Pemerintah Republik Indonesia Nomor 13 Tahun 2015 tentang Standar Nasional Pendidikan. Dalam peraturan pemerintah tersebut dinyatakan bahwa setiap satuan pendidikan pada jalur formal dan nonformal wajib melakukan penjaminan mutu pendidikan. Penjaminan mutu pendidikan tersebut bertujuan untuk memenuhi atau melampaui standar nasional pendidikan (SNP).

Sistem Penjaminan Mutu Pendidikan (SPMP) merupakan suatu sistem yang meliputi : Sistem Penjaminan Mutu Internal (SPMI), dan Sistem Penjaminan Mutu Eksternal (SPME). SPMI merupakan kegiatan penjaminan mutu yang dilaksanakan oleh satuan pendidikan dan dilaksanakan dalam satu siklus penjaminan mutu pendidikan. Siklus tersebut meliputi: tahap penetapan standar, tahap pemetaan mutu, tahap perencanaan peningkatan mutu, tahap pemenuhan mutu, serta tahap monitoring dan evaluasi. Selain SPMI, pemerintah juga telah menetapkan berbagai program kegiatan lain yang dilakukan dalam upaya meningkatkan kompetensi dan kapabilitas peserta didik antara lain Program Penguatan Pendidikan Karakter (PPK), Kurikulum Operasional Sekolah dengan pembelajaran paradigm baru, dan Gerakan Literasi Sekolah (GLS), Asesmen Kompetensi Minimum (AKM) yang meliputi Literasi dan Numerasi, Asesmen Nasional Berbasis Komputer (ANBK) yang terdiri dari AKM (Literasi dan Numerasi), Survei Karakter dan Survei Lingkungan Belajar serta Profil Pelajar Pancasila. Semua program tersebut selayaknya dilakukan secara terpadu bukan terpisah-pisah, sehingga akan mempermudah satuan pendidikan melaksanakan pencapaian mutu.

Secara implementatif, Kemendikbud menerbitkan Permendikbud Nomor 28 Tahun 2016 tentang Sistem Penjaminan Mutu Pendidikan Dasar dan Menengah. Regulasi ini menjadi pedoman bagi semua pihak yang terlibat, termasuk satuan pendidikan dalam melaksanakan penjaminan mutu. Sistem ini mencakup seluruh indikator penyelenggaraan pendidikan dengan memanfaatkan berbagai sumberdaya dan menerapkan keseluruhan siklus dalam sistem penjaminan mutu secara mandiri, partisipatif, terstandar, integritas, sistematis, berkesinambungan, holistik, transparan dan akuntabel sehingga terbangun budaya mutu. Terlaksananya budaya mutu di satuan pendidikan akan mendorong peningkatan mutu yang berkelanjutan dan konsisten dari waktu ke waktu secara bertahap sehingga SNP akan terpenuhi bahkan terlampaui.

Dalam rangka menghadapi tantangan dan perubahan yang terjadi baik di dalam negeri maupun di lingkungan global, berbagai kebijakan baru dikeluarkan oleh Kementerian Pendidikan dan Kebudayaan. Kebijakan ini dimaksudkan untuk meningkatkan daya saing lulusan dalam menghadapi tantangan dan perubahan tersebut. Berbagai kebijakan tersebut diantaranya adalah merdeka belajar, program sekolah penggerak, program guru penggerak, dan pembelajaran jarak jauh (Ahmad, 2020 \& 2021).

Guna mempercepat peningkatan mutu pendidikan dari seluruh satuan pendidikan pada jenjang pendidikan dasar dan jenjang pendidikan menengah, upaya peningkatan kapasitas pengawas sekolah sangat diperlukan. Selama ini, pengawas sekolah telah melakukan supervisi akademik dan manajerial. Model supervisi tersebut merupakan supervisi konvensional. Agar kapasistas pengawas sekolah meningkat dalam membina sekolah binaannya sehingga mutunya makin meningkat mencapai kategori SNP atau bahkan di atas SNP, Direktorat Jenderal PAUD, Pendidikan Dasar, dan Pendidikan Menengah sejak tahun 2019 telah mengembangkan model supervisi mutu. Model supervisi mutu yang telah 
dikembangkan berbasis pada rapor mutu sekolah dan laporan supervisi mutu secara daring. Pada tahun 2021, program tersebut dilanjutkan dan disempurnakan.

Berdasarkan kondisi pandemi Covid-19, Pusat Asesmen dan Pembelajaran (Pusmenjar) kemdikbud melaksanakan secara nasional program Asesmen Nasional Berbasis Komputer (ANBK) untuk jenjang pendidikan dasar dan menengah. Untuk jenjang SD/MI diikuti oleh peserta didik kelas V, jenjang SMP/MTs diikuti oleh kelas VII dan jenajang SMA/SMK/MA diikuti oleh kelas XI. Rangkaian kegiatan program ANBK mulai pada tahun 2021 terdiri atas enam kegiatan, yaitu: (1) kepesertaan AN, (2) pelaksanaan, (3) penyiapan instrument AN, (4) pelaksanaan dan penyiapan teknis, (5) pengolahan dan pelaporan hasil AN dan (6) pemantauan dan evaluasi. Hal ini digunakan untuk menyiapkan pengawas sekolah dalam melakukan pemantauan dan evaluasi pelaksanaan ANBK pada satuan pendidikan yang menjadi binaannya. Dinas Pendidikan Kabupaten Lombok Tengah telah melakukan sosialisasi ANBK untuk pengawas sekolah kepada seluruh pengawas sekolah pada duabelas kecamatan.

Pelaksanaan ANBK telah dilaksanakan oleh satuan pendidikan jenjang sekolah dasar selama rentang waktu selam empat gelombang. Hasil pemantauan pelaksanaan ANBK di sekolah dasar ada yang ditindaklanjuti langsung oleh pengawas sekolah pada saat kegiatan monitoring dan evaluasi. Namun, ada juga hasil pemantuan ANBK yang diselesaikan di kemudian hari berdasarkan jadwal yang disepakati antara pengawas sekolah dan kepala sekolah. Agar hasil pemantauan ANBK dapat ditindaklanjuti lebih komprehensif dan dapat dijadikan sebagai acuan dalam pengambilan kebijakan pada tahun berikutnya, maka perlu dilakukan analisis dan penyusunan laporan hasil pemantauan yang diperoleh. Adapun tujuan penelitian ini adalah untuk mendeskripsikan pemantauan pelaksanaan asesmen nasional berbasis komputer (ANBK) bagi Sekolah Dasar Binaan Kecamatan Kopang Tahun 2021

\section{Metode Penelitian}

Metode penelitian ini menggunakan metode deskriptif. Pemantauan ANBK dilaksanakan untuk mengumpulkan data dan informasi tentang keterlaksanaan ANBK di sekolah dasar. Adapun sumber data dan jenis data yang dikumpulkan serta bagaimana memperoleh data tersebut dijelaskan sebagai berikut ini.

\section{1). Sumber Data.}

Data primer diperoleh dari isian instrumen pemantauan pelaksanaan ANBK yang menggunakan print out yang disiapkan oleh Dinas Pendidikan Kabupaten Lombok Tengah. Data skunder diperoleh dari hasil wawancara dengan beberapa responden dan hasil pengamatan langsung.

2). Data yang Terkumpul.

Data yang terkumpul adalah laporan dalam bentuk word

3). Cara memperoleh data.

a). Pengumpulan data secara langsung (offline).

Pengawas sekolah melakukan pengamatan dan pemantauan di sekolah. Selanjutnya, pengawas sekolah melakukan wawancara dengan responden kepala sekolah, guru, siswa, proctor, teknisi dan pengawas ANBK. Selain melakukan wawancara, pengawas sekolah juga melakukan observasi dokumen dan observasi lingkungan sekolah.

b). Pengumpulan data secara dalam jaringan (online). 
Data yang telah dikumpulkan oleh pengawas sekolah secara langsung dari sekolah kemudian dilaporkan secara online kepada Dinas Pendidikan Kabupaten Lombok tengah.

Data hasil pemantauan pelaksanaan ANBK yang terkumpul kemudian diolah dan dianalisis untuk mendapatkan rekomendasi yang akan ditindaklanjuti. Data tersebut dianalisis secara kualitatif dan kuantitatif. Analisis kualitatif dilakukan untuk memberikan gambaran lebih dalam tentang catatan-catatan deskriptif yang ditemukan selama pemantauan. Analisis kuantitatif digunakan untuk menggambarkan sejauhmana kesiapan sekolah dalam melaksanakan ANBK dilihat dari sisi: (1) identitas sekolah dengan akreditasinya; (2) informasi kelembagaan yang mandiri, menumpang dan ditumpangi; (3) jumlah peserta didik yang mengikuti baik laki maupun perempauan; (4) jadwal pelaksanaan ANBK; (5) ketenagaan yang terdiri dari proktor, teknisi dan pengawas; (6) sarana pelaksanaan berupa server, UPS, genset, daya listrik dan kapsitas internet; (7) tata tertib dan pengumuman; (8) hari, tanggal, waktu, mata pelajaran,sesi dan kehadiran peserta didik; (9) komentar hambatan dari segi keamanan, kesiapan, fasilitas, program aplikasi, dan kejadian lain yang terjadi pada setiap sesi dan; (10) upaya mengatasi hambatan atau permasalahan yang terjadi.

\section{Hasil Penelitian dan Pembahasan \\ Rerata Capaian Pemantauan ANBK.}

1. Capaian Identitas Sekolah dan Akreditasinya.

Rerata hasil pemantauan indikator ini dapat dilihat pada tabel 1 berikut.

Tabel 1. Rerata Capaian Indikator Identitas Sekolah dan Akreditasinya

\begin{tabular}{|l|l|c|}
\hline Identitas Sekolah & \multicolumn{1}{|c|}{ Alamat Sekolah } & Akreditasi \\
\hline SDN Renggung & Kopang Rembiga & A \\
\hline SDN Puyung & Kopang Rembiga & B \\
\hline SDN Penimpoh & Montong Gamang & B \\
\hline SDN Jurit & Bebuak & B \\
\hline SDN Kwang Pati & Lendang Ara & B \\
\hline
\end{tabular}

Tabel diatas menunjukkan data rerata hasil akreditasinya adalah $\mathrm{B}$, dimana ada satu SD yang memperoleh akreditasi A yaitu SDN Renggung, sedangkan yang lainnya masih akreditasinya B. dengan demikian maka empat sekolah dasar di atas perlu meningkatkan kinerjanya untuk mencapai akreditas yang lebih tinggi.

2. Capaian Data Informasi Kelembagaan

Informasi Kelembagaan penyelenggara ANBK meliputi; (1) sekolah mandiri, (2) sekolah menumpang dan, (3) sekolah ditumpangi. Data kelembagaan pelaksanaan ANBK ditunjukkan dengan tabel 2 berikut.

Tabel 2. Kelembagaan ANBK

\begin{tabular}{|l|c|c|c|}
\hline Kelembagaan & Mandiri & Menumpang & Ditumpangi \\
\hline SDN Renggung & V & - & - \\
\hline SDN Puyung & V & - & - \\
\hline SDN Penimpoh & V & - & - \\
\hline SDN Jurit & V & - & - \\
\hline SDN Kwang Pati & V & - & - \\
\hline
\end{tabular}

Tabel diatas menunjukkan bahwa dari lima SD tersebut melaksanakan ANBK secara mandiri di sekolah masing-masing, tidak ada sekolah yang menumpang dan ditumpangi. Hal ini disebabkan oleh karena setiap sekolah menyelenggarakan ANBK dengan system sesi setiap 
gelombang. Setiap gelombang diikuti oleh sepuluh orang dengan ketentuan sesi pertama pada pagi hari sebanyak lima orang dan sesi kedua pada siang hari sebanyak lima orang dengan jumlah perangkat computer/laptop minimal 5 unit.

\section{Capaian Jumlah Peserta ANBK}

Jumlah peserta didik yang mengikuti ANBK di setiap sekolah yang dipantau mencapai 100\%. Karena sekolah mempersiapkan peserta didiknya sesuai Daftar Nominasi Sementara (DNS) yang ditetapkan oleh Dinas Pendidikan Kabupaten Lombok Tengah, dan selanjutnya ditetapkan menjadi Daftar Nominasi Tetap (DNT) oleh procktor melalui aplikasi dan sinkronisasi. Tabel 4.3 menunjukan jumlah peserta ANBK menurut jenis kelamin dari lima sekolah yang dipantau,terdapat pesserta laki-laki sebanyak 67 orang dan perempuan sebanyak 40 orang. Seluruh peserta yang ikut dalam kegiatan ANBK sebanyak 107 orang.

\begin{tabular}{|l|c|c|c|}
\multicolumn{2}{c}{ Tabel 3. Jumlah Peserta ANBK Menurut Jenis Kelamin } \\
\cline { 2 - 4 } \multicolumn{1}{|c|}{ Sekolah Asal } & \multicolumn{3}{|c|}{ Peserta ANBK } \\
\cline { 2 - 4 } & Laki & Perempuan & Jumlah \\
\hline SDN Renggung & 20 & 10 & 30 \\
\hline SDN Puyung & 7 & 6 & 13 \\
\hline SDN Penimpoh & 5 & 13 & 30 \\
\hline SDN Jurit & 17 & 4 & 22 \\
\hline SDN Kwang Pati & 18 & $\mathbf{4 0}$ & $\mathbf{1 0 7}$ \\
\hline JUMLAH & $\mathbf{6 7}$ & &
\end{tabular}

\section{Capaian Jadwal Pelaksanaan ANBK}

Jadwal pelaksanaan ANBK pada lima sekolah dasar yang dipantau di masa pandemi dipakai berdasarkan Standar Operasional Prosedur (SOP) dan petunjuk teknis yang dikeluarkan oleh Dinas Pendidikan Kabupaten Lombok Tengah. Pengaturan jadwal pelaksanaannya sesuai dengan keadaan fasilitas sekolah dan telah disepakati menggunakan lima komputer/laptop peserta dengan dua sesi perhari dan diikuti peserta sejumlah lima orang sebagaimana tertera dalam tabel 4 berikuy.

Tabel 4. Jadwal Pelaksanaan ANBK

\begin{tabular}{|l|c|c|}
\hline \multicolumn{1}{|c|}{ Hari ke.. } & \multicolumn{1}{c|}{ Tanggal } & Jumlah Sesi \\
\hline Hari Pertama & 15 November 2021 & 2 \\
\hline Hari Kedua & 16 November 2021 & 2 \\
\hline Hari Ketiga & 17 November 2021 & 2 \\
\hline Hari Keempat & 18 November 2021 & 2 \\
\hline
\end{tabular}

\section{Capaian Ketenagaan}

Peran proktor, teknisi dan pengawas AN dalam pelaksanaan ANBK di masa pandemi Covid19 ini sangat strategis. Setiap sekolah penyelenggara membentuk tim tersebut berdasarkan kemampuan IT dari personil yang akan ditunjuk, baik proctor, teknisi, maupun pengawas AN. Pengawasan AN dilaksanakan dengan sitem silang penuh dalam gugus sekolah tersebut, untuk menjaga kerahasiaan, tranfaransi dan akuntabilitas pelaksanaan ANBK dimaksud. Tabel 4.5 menunjukkan sebaran ketenagaan.

Tabel 5. Distribusi Ketenagaan Setiap Sekolah

\begin{tabular}{|l|c|c|c|c|}
\hline Nama Sekolah & Proktor & Teknisi & Pengawas & Jumlah \\
\hline SDN Renggung & 1 & 1 & 1 & 3 \\
\hline SDN Puyung & 1 & 1 & 1 & 3 \\
\hline
\end{tabular}




\begin{tabular}{|l|c|c|c|c|}
\hline SDN Penimpoh & 1 & 1 & 1 & 3 \\
\hline SDN Jurit & 1 & 1 & 1 & 3 \\
\hline SDN Kwang Pati & 1 & 1 & 1 & 3 \\
\hline \multicolumn{1}{|c|}{ JUMLAH } & $\mathbf{5}$ & $\mathbf{5}$ & $\mathbf{5}$ & $\mathbf{1 5}$ \\
\hline
\end{tabular}

\section{Capaian Sarana dan Prasarana ANBK}

Bagi satuan pendidikan yang pelaksanaan ANBK ditempatnya sendiri secara mandiri disiapkan ruangan dengan jumlah komputer atau laptop. Begitu juga bagi sekolah yang menumpang atau ditumpangi. Capaian hasil pemantauan terhadap sarana dan prasarana yang digunakan dalam pelaksanaan ANBK pada setiap sekolah ditunjukkan pada tabel 4.6. Kelima sekolah yang dipantau tidak ada yang memiliki server dan genset. Hal ini disebabkan karena kelima sekolah tersebut menggunakan moda daring dan tidak pernah padam listrik selama pelaksanaan ANBK. Kemampuan kapasitas internet (bandwidth) rata-rata bagus , sinyalnya kuat, dan kencang karena semua sekolah menggunakan perangkat internet yang dinamakan dengan sebutan "Modem Orbit".

Tabel 6. Data Sarana dan Prasarana Pelaksanaan ANBK

\begin{tabular}{|l|c|c|c|c|c|}
\hline \multicolumn{1}{|c|}{ Sekolah } & Server & UPS & Genset & Listrik & Internet \\
\hline SDN Renggung & - & 7 & - & 1300 & 10 \\
\hline SDN Puyung & - & 4 & - & 900 & 10 \\
\hline SDN Penimpoh & - & 7 & - & 450 & 17 \\
\hline SDN Jurit & - & 7 & - & 900 & 10 \\
\hline SDN Kwang Pati & - & 6 & - & 1300 & 17 \\
\hline
\end{tabular}

\section{Capaian Tata tertib dan Pengumuman}

Semua sekolah dasar yang dipantau telah menggunakan tata tertib dan pengumuman yang harus dipasang di lokasi ANBK. Tata tertib, baik bagi peserta ANBK, proctor, teknisi maupun pengawas AN terpampang di pintu atau jendela ruangan pelaksanaan ANBK. Selanjutnya pengumuman yang berisi empat kalimat terpampang dalam bentuk spanduk serta dapat dibaca dari kejauhan.

8. Capaian Hari, Tanggal, Waktu, Mata Pelajaran, Sesi Kehadiran Peserta ANBK Pada saat pelaksanaan pemantauan ANBK tercatat sesi pada hari dan tanggal dilaksanakan pada pukul berapa, mata pelajaran yang diasesmenkan beserta kehadiran peserta didik yang mengikuti ANBK pada sesi tersebut. Tabel 4.7 menunjukkan bahwa selama pelaksanaan ANBK dari sesi ke sesi tidak ada peserta ANBK yang tidak hadir. Di samping itu pada hari pertama seriap sesi dijadwalkan mata pelajaran "Literasi Membaca dan Survei Karakter", sedangkan hari kedua dengan mata pelajaran "Numerasi dan Survei Lingkungan Belajar".

Tabel 7. Pengaturan Asesmen Jenjang SD

\begin{tabular}{|c|c|l|l|}
\hline Sesi & Waktu & \multicolumn{1}{c|}{ Jenis Asesmen } & Pelaksanaan \\
\hline \multicolumn{3}{|c|}{ Hari/tanggal , Senin - Kamis, 15 - 18 November 2021 } \\
\hline I & $08.00-10.35$ & Latihan (60 menit) & \multirow{3}{*}{ Hari Pertama } \\
\cline { 3 - 4 } & & Literasi (75 menit) & \multirow{3}{*}{ Hari Kedua } \\
\cline { 3 - 4 } II & $13.00-15.35$ & Survei Karakter (20 menit) & \\
\hline I & $08.00-10.35$ & Latihan (25 menit) & \\
\cline { 3 - 4 } & & Numerasi (75 menit) & \\
\cline { 3 - 4 } II & $13.00-15.00$ & Survei Lingkungan Belajar (20 menit) & \\
\hline \multicolumn{4}{|c|}{ Hari/tanggal, Senin - Kamis, 22 - 25 November 2021 } \\
\hline I & $08.00-10.35$ & Latihan (60 menit) & \\
\hline
\end{tabular}




\begin{tabular}{|c|c|l|l|}
\hline & & Literasi (75 menit) & \multirow{2}{*}{ Hari Pertama } \\
\cline { 3 - 3 } II & $13.00-15.35$ & Survei Karakter (20 menit) & \\
\hline I & $08.00-10.35$ & Latihan (25 menit) & \multirow{3}{*}{ Hari Kedua } \\
\cline { 3 - 3 } & & Numerasi (75 menit) & \\
\cline { 3 - 4 } II & $13.00-15.00$ & Survei Lingkungan Belajar (20 menit) & \\
\hline
\end{tabular}

Bagi pendidik dan kepala satuan pendidikan pada lima sekolah yang dipantau mengikuti asesmen tentang "Survei Lingkungan Belajar" secara mandiri selama 20 menit dengan rentang waktu empat hari sejalan dengan pelaksanaan ANBK di sekolah masing-masing.

\section{Capaian Hambatan Pelaksanaan ANBK}

Selama pelaksanaan ANBK pada lima sekolah dasar yang dilakukan pemantauan, tidak mengalami hambatan yang signifikan, hanya hambatan kecil yang saat itu dapat diatasi oleh proktor yang bertugas di lokasi ANBK. Peserta didik merasa nyaman, dan aman walaupun peserta didik yang lainnya tetap masuk belajar di sekolah. Sekolah sudah siap siaga dan menyediakan fasilitas sesuai kondisi sekolah masing-masing. Program aplikasi ANBK sudah mampu diupdate pada setiap perangkat yang ada.

\section{Upaya Tindakan Mengatasi Hambatan Pelaksanaan ANBK}

Dari hambatan yang kecil dapat diatasi secara cepat oleh tim yang bekerja. Terbangunnya kerja sama yang baik diantara proctor, teknisi, pengawas AN, dan panitia penyelenggara di sekolah. Karena peserta didik kelas 1, 2, 3, 4, dan 6 tetap masuk belajar di sekolah, maka ada sedikit gangguan kenyamanan peserta ANBK. Hal ini dapat diatasi dengan diberikan tugas bagi peserta didik yang tidak mengikuti ANBK untuk diselesaikan di rumah dengan sistem belajar dari rumah (BDR) selama pelaksanaan ANBK berlangsung. Di samping itu, ada juga perangkat yang macet dalam pemakaiannya dilakukan pergantian dengan perangkat cadangan yang telah disiapkan sekolah. Pengiriman jawaban yang memerlukan waktu lama dalam loading dilakukan pengiriman ulang dengan token yang berbeda, sehingga semua jawaban peserta ANBK terkirim seluruhnya, termasuk administrasi bukti penyelenggaraannya seperti daftar hadir dan berita acara.

\section{Rekap Data Hasil Pelaksanaan Pemantauan ANBK}

Rekap data hasil pelaksanaan pemantauan ANBK pada lima sekolah dasar yang dilakukan pemantauan sebagaimana tercantum dalam tabel 8 .

Tabel 8. Rekap Data Hasil Pemantauan ANBK

\begin{tabular}{|l|c|c|c|c|c|c|c|c|c|}
\hline \multicolumn{1}{|c|}{ Sekolah } & Akreditasi & Sistem & Sesi & Tenaga & Peserta & UPS & Listrik & Internet & $\begin{array}{c}\text { Hadir } \\
(\mathbf{\%})\end{array}$ \\
\hline Renggung & $\mathrm{A}$ & $\mathrm{M}$ & 2 & 3 & 30 & 7 & 1300 & 10 & 100 \\
\hline Puyung & $\mathrm{B}$ & $\mathrm{M}$ & 2 & 3 & 13 & 4 & 900 & 10 & 100 \\
\hline Penimpoh & $\mathrm{B}$ & $\mathrm{M}$ & 2 & 3 & 12 & 7 & 450 & 17 & 100 \\
\hline Jurit & $\mathrm{B}$ & $\mathrm{M}$ & 2 & 3 & 30 & 7 & 900 & 10 & 100 \\
\hline Kwang Pati & $\mathrm{B}$ & $\mathrm{M}$ & 2 & 3 & 22 & 6 & 1300 & 17 & 100 \\
\hline
\end{tabular}

Keterangan :

a) Sekolah memiliki nilai akreditasi $\mathrm{A}$ dan $\mathrm{B}$

b) Sekolah menyelenggarakan ANBK secara mandiri (M) dengan sistem daring tanpa server.

c) Sekolah menyelenggarakan ANBK dengan dua sesi setiap hari selama pelaksanaan ANBK. 
d) Sekolah mengikutsertakan peserta ANBK sesuai dengan Daftar Nominasi Tetap (DNT).

e) Sekolah menyiapkan pernagkat UPS sesuai kemampuan masing-masing.

f) Daya listrik yang terpasang pada setiap sekolah antara 450 - 1300 watt.

g) Kapasitas internet (bandwidth) antara $10-20 \mathrm{mbps}$

h) Semua peserta ANBK yang terdapat dalam DNT hadir semua dengan prosentase kehadiran $100 \%$.

\section{Tindakan dan Rekomendasi.}

Dari data hasil dan pembahasan tentang pemantauan pelaksanaan ANBK pada jenjang sekolah dasat yang dilakukan pemantauan disampaikan beberapa tindakan yang dapat dilakukan dan rekomendasi yang diajukan kepada pihak-pihak terkait dalam rangka meningkatkan penyelenggaraan ANBK sehingga mutu pendidikan meningkat baik pada satuan pendidikan, maupun Dinas Pendidikan Kabupaten Lombok Tengah.

1) Tindakan yang dapat dilakukan.

a) Ketika peserta ANBK kurang merasa nyaman dan aman saat pelaksanaan, maka peserta didik yang tidak mengikuti ANBK diberikan tugas-tugas untuk diselesaikan di rumah, karena pendidik yang ada di sekolah semuanya bertugas baik panitia, proktor, teniksi, maupun pengawas AN.

b) Ketika kapasitas internet tidak kuat dan sinyalnya terputus-putus, maka sekolah segera menyiapkan modem orbit yang kapasitasnya kencang.

c) Ketika salah satu UPS rusak atau gangguan pada peserta ANBK, maka teknisi segera mengganti dengan UPS cadangan yang siaga di ruang ANBK

d) Ketiak peserta ANBK megalami kendala dalam pengiriman jawaban, maka proktor segera memberikan token kembali untuk mengirim ulang kembali.

2) Rekomendasi yang diajukan.

Beberapa rekomendasi yang diusulkan baik kepada satuan pendidikan maupun Dinas

Pendidikan Kabupaten Lombok untuk perbaikan di masa mendatang antara lain :

a) Peningkatan kompetensi pendidik dan tenaga kependidikan dalam menyusun soal-soal yang berorientasi literasi dan numerasi pada setiap mata pelajaran melalui workshop.

b) Peningkatan kapasitas pendidik dan tenaga kependidikan dalam menerapkan digitalisasi sekolah melalui IHT.

c) Peningkatan penyediaan sarana dan prasarana ANBK dengan pengadaan ruang laboratorium IT minimal satu unit dalam satu gugus sekolah melalui DAK

d) Peningkatan ketersedian perangkat computer/laptop melalui pemanfaatan dana BOS Reguler/Afirmasi/Kinerja.

e) Peningkatan kapasitas kepala sekolah dalam manajemen pengelolaan sekolah

f) Peningkatan kapasitas pengawas sekolah dalam pengawasan akademik dan pengawasan manajerial.

g) Pemberdayaan wadah KKG, KKKS dan KKPS dalam menyelesaikan tugas pokok dan fungsi masing-masing

\section{Kesimpulan}

Dari uraian di atas dapat digambarkan bahwa ketika peserta ANBK kurang merasa nyaman dan aman saat pelaksanaan, maka peserta didik yang tidak mengikuti ANBK diberikan tugas-tugas untuk diselesaikan di rumah, karena pendidik yang ada di sekolah 
semuanya bertugas baik panitia, proktor, teniksi, maupun pengawas AN. Ketika kapasitas internet tidak kuat dan sinyalnya terputus-putus, maka sekolah segera menyiapkan modem orbit yang kapasitasnya kencang. Ketika salah satu UPS rusak atau gangguan pada peserta ANBK, maka teknisi segera mengganti dengan UPS cadangan yang siaga di ruang ANBK. Ketiak peserta ANBK megalami kendala dalam pengiriman jawaban, maka proktor segera memberikan token kembali untuk mengirim ulang kembali. Berdasarkan berbagai asumsi tindakan diatas, maka ditarik beberapa simpulan antara lain untuk dapat meningkatkan kualitas dan kuantitas mutu pelaksanan ANBK di masa mendatang sangat perlu untuk:

1) Peningkatan kompetensi pendidik dan tenaga kependidikan dalam menyusun soalsoal yang berorientasi literasi dan numerasi pada setiap mata pelajaran melalui workshop.

2. Peningkatan kapasitas pendidik dan tenaga kependidikan dalam menerapkan digitalisasi sekolah melalui IHT.

3. Peningkatan penyediaan sarana dan prasarana ANBK dengan pengadaan ruang laboratorium IT minimal satu unit dalam satu gugus sekolah melalui DAK

4. Peningkatan ketersedian perangkat computer/laptop melalui pemanfaatan dana BOS Reguler/Afirmasi/Kinerja.

5. Peningkatan kapasitas kepala sekolah dalam manajemen pengelolaan sekolah

6. Peningkatan kapasitas pengawas sekolah dalam pengawasan akademik dan pengawasan manajerial.

7. Pemberdayaan wadah KKG, KKKS dan KKPS dalam menyelesaikan tugas pokok dan fungsi masing-masing

\section{Saran}

Saran terhadap pelaksanaan hasil pemantauan atas keterlaksanaan kegiatan penyelenggaraan ANBK disampaikan saran-saran berikut ini.

\section{1) Saran untuk Sekolah.}

a) Sekolah perlu melaksanakan segala rekomendasi dan tindaklanjut hasil pemantauan ANBK agar hasilnya akan lebih baik di masa mendatang.

b) Sekolah perlu memprogramkan kegiatan peningkatan persiapan dan pelaksanaan ANBK ke dalam RKAS.

c) Sekolah hendaknya berkoordinasi dengan pengawas sekolah dalam menyusun rencana pengembangan sekolah dalam aspek pelaksanaan ANBK.

d) Sekolah hendaknya memperbanyak volume kegiatan pembimbingan dan pelatihan guru dan/atau kepala sekolah dengan narasumber pengawas sekolah pembinanya atau narasumber lainnya demi peningkatan kapasitas pendidik dan tenaga kependidikan yang ada di sekolah.

\section{2) Saran untuk Dinas Pendidikan Kabupaten Lombok tengah.}

a) Perlu menganggarkan biaya operasional pelaksanaan ANBK di satuan pendidikan berasal dari APBD.

b) Perlu merencanakan tambahan operasional sekolah berupa BOSDA baik kabupaten maupun provinsi.

c) Hendaknya dapat melaksanakan rekomendasi dan rencana tindaklanjut dari setiap capaian hasil pemantauan agar apa yang dituangkan dalam laporan ini mempunyai makna yang tinggi. 
d) Pemerintah daerah atau lembaga terkait hendaknya dapat memberikan penghargaan kepada pengawas sekolah yang telah melaksanakan dan menyampaikan laporannya baik dalam bentuk material maupun moril.

e) Perlu dianggarkan bagi pengawas sekolah berupa ATK dan biaya operasional pelaksanaan tugas pokok dan fungsi agar kualitas dan kuantitas lebih maksimal

3) Saran untuk Pengawas Sekolah.

a)Pengawas sekolah hendaknya secara terus menerus dan berkesinambungan dapat melaksanakan pendampingan pada sekolah binaannya tanpa harus menunggu program tersebut dari Dinas Pendidikan Kabupaten Lombok Tengah.

b) Pengawas sekolah hendaknya setiap melakukan kegiatan pembinaan guru dan/atau kepala sekolah, memyampaikan laporan secara tertulis kepada pemangku kepentingan agar dapat dijadikan acuan pengambilan kebijakan strategis kaitan dengan peningkatan mutu pendidikan di daerah.

\section{Daftar Pustaka}

Ahmad, A. (2021). Implementasi Pembinaan Konsepsi Model Pembelajaran Up Grading untuk Meningkatkan Kualitas Mengajar Guru di Sekolah Dasar Binaan Segugus 05 Kopang Lombok Tengah. Jurnal Teknologi Pendidikan : Jurnal Penelitian dan Pengembangan Pembelajaran, 6(2), 128-141. doi:https://doi.org/10.33394/jtp.v6i2.4234

Ahmad, A. (2020). Peningkatan Kompetensi Pedagogik Guru dalam Pembelajaran Jarak Jauh Melalui Pendampingan Sistem Daring, Luring, atau Kombinasi pada Masa New Normal Covid-19. Jurnal Paedagogy, 7(4), 258-264. doi:https://doi.org/10.33394/jp.v7i4.2803

Badan Standar Kurikulum dan Asesmen Pendidikan. (2021). Prosedur Operasional Standar Penyelenggaraan Asesmen Nasional Tahun 2021. Jakarta: Kemdikburistek

Bafadal, Ibrahim, (2005). Dasar-dasar Manajemen dan Supervisi Taman Kanak-kanak. Jakarta: Bumi Aksara.

Depdiknas. (2003). Undang-Undang Nomor 20 Tahun 2003 tentang Sistem Pendidikan Nasional. Jakarta: Dirjen Dikdasmen.

Disdik.Lombok Tengah.(2021). Petunjuk Teknis Penyelenggaraan Asesmen Nasional (AN) Pada SD, SMP, Paket A, dan Paket B Kabupaten Lombok Tengah Tahun 2021. Praya. Disdik

Imron, A. (2011). Supervisi Pembelajaran Tingkat Satuan Pendidikan. Jakarta: Bumi Aksara Kemdikbud, (2007). Permendiknas No. 24 Tahun 2007 tentang Standar Sarana dan Prasarana Sekolah/Madrasah Pendidikan Umum. Jakarta: Kemdikbud.

Kemdikbud, (2015). Peraturan Presiden Nomor 14 Tahun 2015 tentang Kementerian Pendidikan dan Kebudayaan. Jakarta: Depdiknas.

Kemdikbud, (2015). Peraturan Pemerintah Nomor 19 Tahun 2005 tentang Standar Nasional Pendidikan sebagaimana telah diubah dengan Peraturan Pemerintah RI Nomor 32 Tahun 2013 tentang perubahan atas Peraturan Pemerintah Nomor 19 Tahun 2005 Tentang Standar Nasional Pendidikan dan Peraturan Pemerintah Nomor 13 Tahun 2015 tentang Perubahan Kedua atas Peraturan Pemerintah Nomor 19 Tahun 2005 tentang Standar Nasional Pendidikan. Jakarta: Kemdikbud.

Kemdikbud, (2015). Peraturan Menteri Pendidikan dan Kebudayaan Nomor 11 Tahun 2015 tentang Organisasi dan Tata Kerja Kementerian Pendidikan dan Kebudayaan. Jakarta: Kemdikbud. 
Kemdikbud, (2016). Permendikbud No. 22 Tahun 2016 tentang Standar Proses; Permendikbud No. 23 Tahun 2016 tentang Standar Penilaian. Jakarta: Kemdikbud.

Kemdikbud, (2016). Permendikbud Nomor 28 tahun 2016 tentang Sistem Penjaminan Mutu Pendidikan Dasar dan Menengah. Jakarta: Kemdikbud.

Kemdikbud, (2021). Konsep Supervisi Mutu. Jakarta: DirJen Pendidikan Anak Usia Dini, Pendidikan Dasar Dan Menengah

Kemdikbud, (2015). Peraturan Presiden Nomor 14 Tahun 2015 Tentang Kementerian Pendidikan dan Kebudayaan. Jakarta: Depdiknas.

Kemdikbud. (2015). Peraturan Menteri Pendidikan dan Kebudayaan Nomor 11 Tahun 2015 tentang Organisasi dan Tata Kerja Kementerian Pendidikan dan Kebudayaan. Jakarta: Kemdikbud.

Kurniati (2016). No Title. Pendekatan Supervisi Pendidikan From http://journal.uinalauddin.ac.id/index.php/idaarah/article/view/7894

Kompasiana.com/hafismuaddab/5500b8a0a33311531850fa56/paradigma-input-dan-outputpendidikan?page=all. 2011

Ma Saong, Abd. Kadim, (2013). Supervisi Pembelajaran dan Pengembangan Kapasitas Guru. Jakarta: Alfabeta.

Piet A. Sahertian, (2000). Konsep Dasar Dan Tehnik Supervisi Pendidikan: Dalam Rangka Pengembangan Sumber Daya Manusia, (Jakarta: Rineka Cipta, 2000), hlm. 44.

Sabandi, Ahmad. (2013). "Supervisi Pendidikan Untuk Pengembangan Profesionalitas Guru Berkelanjutan." Pedagogi, Jurnal Ilmiah Ilmu Pendidikan XIII(2): 1-9. http://ejournal.unp.ac.id/index.php/pedagogi/article/view/4275.

Sagala, Syaiful, (2009). Kemampuan Profesional Guru dan Tenaga Kependidikan. Bandung: Alfabeta. 